\title{
THE EFFECTS OF BIOTECHNOLOGY ON PRODUCTIVITY AND INPUT DEMANDS IN U.S. AGRICULTURE
}

\author{
JEAN-PAUL CHAVAS* \\ Department of Agricultural and Applied Economics, University of Wisconsin, Madison, Wisconsin \\ GUANMING SHI \\ Department of Agricultural and Applied Economics, University of Wisconsin, Madison, Wisconsin \\ RICHARD NEHRING \\ Economic Research Service, U.S. Department of Agriculture, Washington, DC \\ KYLE STIEGERT \\ Department of Agricultural and Applied Economics, University of Wisconsin, Madison, Wisconsin
}

\begin{abstract}
U.S. agriculture has seen a rapid adoption of biotechnology over the last two decades. This study investigates how biotechnology has affected U.S. farm input demand and agricultural productivity. The analysis relies on data at the national level and at the state level for selected states in the Corn Belt. It evaluates the rate of technological change and price elasticities of demand for agricultural inputs over time. The study documents the evolving biases in technological change in agriculture. It finds evidence that farm input demands have become more price inelastic.
\end{abstract}

Keywords. Agriculture, biotechnology, input demand, technological change

JEL Classifications. D22, D24, O33, Q16

\section{Introduction}

Over the last few decades, U.S. agriculture has benefited from rapid increases in farm productivity (Wang et al., 2015), driven primarily by technological innovations and improved farm management. Higher productivity has contributed to increased profitability and competitiveness of U.S. farmers in a global marketplace. Fertilizer use has helped maintain or enhance soil productivity; pesticides have contributed to reducing the adverse effects of pest

\footnotetext{
*Corresponding author’s e-mail: jchavas@wisc.edu
}

We thank James MacDonald and three anonymous reviewers for useful comments on an earlier draft of the paper. This paper was financially supported in part by a research grant from the U.S. Department of Agriculture (USDA), National Institute of Food and Agriculture and a cooperative agreement with the USDA. 
damages; and biotechnology has joined with traditional breeding methods to improve the desired genetic characteristics of seeds in agriculture. In particular, since its inception of commercialization in 1996, the world has seen a rapid growth in genetically modified (GM) crops planted in both developed and developing countries. It has generated much interest in evaluating the effects of biotechnology on agriculture (e.g., Bustos, Caprettini, and Ponticelli, 2016; Carpenter, 2010; Klümper and Qaim, 2014; Perry, Moschini, and Hennessy, 2016). The United States is currently the leading adopter of GM staple crops, with adoption rates exceeding $90 \%$ each for GM soybean, cotton, and corn (Fernandez-Cornejo et al., 2014; USDA, 2017a).

This study seeks to develop a greater understanding of the implications of GM technology adoption on the farm demand for inputs. Of special interest is evaluating the distinct effects between two aspects of GM technology: Bt technology (relying on gene transfer from Bacillus thuringiensis), which helps control the pest population for corn and cotton; and herbicide tolerance (HT) technology, which helps control weeds for corn, soybean, and cotton (FernandezCornejo et al., 2012, 2014; Gardner, Nehring, and Nelson, 2009; Perry et al., 2016; Xu et al., 2013). In general, GM seeds can have a considerable impact on pesticide use, but the impact may be different for insecticide use versus herbicide use. GM corn with corn borer and rootworm insect resistance can lead to lower insecticide applications. Yet the GM crop with HT traits may lead to more or lower herbicide applications depending on farm practices. Perry, Moschini, and Hennessy (2016) found that HT traits and conservation tillage are complements. Biotech traits may also act as a substitute for crop rotation to some extent (Chavas, Shi, and Lauer, 2014). In the past, farmers rotated corn and soybeans to keep targeted insects from gaining a foothold on specific plots of farmland. However, in the GM seed era, each plant is protected and insects have limited ability to survive in GM fields; thus, farmers adopting GM may use less crop rotation in planting. Moving away from flexible rotation strategies could alter the demand elasticities for inputs in ways that affect the exercise of market power by agricultural input firms and the pricing of farm inputs. This study examines these issues, thus shedding new light on the economic effects of biotechnology on U.S. agriculture.

Our analysis relies on the estimation of a cost function and the corresponding input cost shares conditional on input prices, intermediate output, and technology. Such an approach provides the information needed for our investigation, including the evaluation of technological change, the temporal effects of biotechnology, and the evolving nature of price elasticities of input demands. However, it faces a significant challenge: agricultural production is risky as factors such as drought and pest damages can have unpredictable effects on farm output. Yet farm inputs are typically chosen ex ante-that is, before risky shocks become realized (e.g., fertilizer use is decided before weather conditions are known). For risk-averse farmers, it implies that farm input 
demands must depend on the distribution of risky output (Pope and Chavas, 1994). ${ }^{1}$ It means that, unlike standard cost minimization, input demands cannot depend on actual output as it is unobserved ex ante (LaFrance and Pope, 2010). This study deals with this issue by relying on a cost function that depends not on final output but rather on intermediate output. LaFrance and Pope (2010) showed that the validity of standard cost minimization can be restored under a weakly separable production function. Following similar arguments, we assume a weakly separable production function and rely on a cost function conditional on intermediate output. In this context, standard cost minimization remains valid under production uncertainty and risk aversion, thus providing the conceptual framework for our analysis.

The analysis is applied to U.S. agriculture, relying on two data sets: time series data on farm inputs and output at the U.S. level over the period 1960-2013 and time series data from nine Corn Belt states over the period 1960-2004. The data on Corn Belt states are of interest as the Corn Belt experienced the largest impact of GM technology. Unfortunately, the state-level data end in 2004 (when the U.S. Department of Agriculture [USDA] stopped collecting data on farm labor at the state level). The U.S.-level data have the advantage of covering the post-2004 period, when GM adoption became widespread for corn, soybean, and cotton. The analysis involves the estimation of demands for six inputs: (1) labor, (2) energy, (3) fertilizer, (4) herbicides, (5) insecticides, and (6) other inputs. The distinction between herbicide and insecticide is of special interest for two reasons. First, distinguishing between herbicide and insecticide is apparently new in the analysis of agricultural productivity and technological change bias. Second, studying the linkages between herbicide demand, pesticide demand, and biotechnology adoption is of significant interest to farmers, researchers, and policy makers (as biotechnology generates new ways to manage weed and pest control).

Our investigation documents how technology has affected farm productivity and input demands. Although the rapid productivity growth has been a common feature of U.S. agriculture over the last few decades, our analysis examines the changing patterns of productivity under biotechnology. It finds that biotechnology has contributed to speeding up productivity growth in the Corn Belt, but not at the U.S. level. It also documents the evolving biases in technological change in agriculture. We find that Bt and HT technologies have different impacts on farm input demands. Bt technology has increased the bias in favor of fertilizer use. By reducing pest damages, this finding indicates that $\mathrm{Bt}$ technology makes it easier for the plant to benefit from fertilizer applications. HT technology, however, tends to be fertilizer saving. The fertilizer-saving bias may reflect that improved weed control increases the availability of soil nutrients

1 Evaluating the output distribution (e.g., using mean, variance, and skewness) can be empirically difficult. Representing the output distribution using a state-contingent approach is another way to proceed, but a state-contingent approach also faces its own empirical challenges (e.g., Chavas, 2008). 
to the plant, thus reducing the need for fertilizer applications. Finally, we find evidence that farm demands for fertilizer, herbicide, and insecticide have become more inelastic after the GM inception (i.e., less responsive to prices). Thus, although biotechnology has contributed to technological progress in agriculture, GM adoption has also been associated with more restricted choices and a lower ability of farmers to adjust to changing market conditions.

The rest of the article is organized as follows: Section 2 presents our model of input choice, motivating our cost function approach. Relying on a translog cost specification, Section 3 presents an application to U.S. agriculture. The econometric results are presented in Section 4. The economic implications of our analysis are examined in Section 5. Finally, Section 6 concludes.

\section{A Model of Input Choice}

This section presents the conceptual approach to our analysis. Consider a production process involving inputs $x \in \mathbb{R}_{+}^{n}$ and capital $K$ in producing output $z$ under production uncertainty. The production function $g(x, t, K, u)$ represents the largest possible output $z$ that can be obtained using factors $(x, K)$ under technology $t$ in the presence of a stochastic shock $u$ (e.g., weather event and/or infestation shock). ${ }^{2}$ As discussed in the introduction, farm input decisions are often made before stochastic production shocks are known, implying that input demand cannot depend on actual output (as in standard cost minimization; see LaFrance and Pope, 2010). Instead, input demand would depend on the perceived distribution of final output (e.g., Pope and Chavas, 1994). Rather than trying to measure this distribution, our study uses a modified approach that can reinstate the validity of standard cost minimization. Following LaFrance and Pope (2010), assuming a weakly separable production function provides the proper analytical framework. In our analysis, we propose to distinguish between actual final output (that is subject to production shocks) and an "intermediate output" (that is immune to uncertainty). In this context, we assume that the production function is weakly separable and can be decomposed into two stages: in stage 1, under technology $\boldsymbol{t}$, inputs $x$ are used to produce intermediate output $y=f(x, t)$; in stage 2 , the intermediate output $y$ is combined with capital $K$ under stochastic shock $u$ to produce output $z=g_{0}(f(x, t), K, u)=g(x, t, K, u)$. Note that this specification restricts technology $t$ to affect only the intermediate output $y$ in the first stage of the production process. It allows for arbitrary possibilities of substitution among inputs $x$ and imposes no restrictions on the effects of technology $t$ on input productivity, nor on the effects of $(K, u)$ on final output $z$.

2 Our analysis focuses on technology and input demands. For simplicity, it is presented assuming a single output. As such, it neglects economic issues (such as economies of scope) that would arise in a multioutput context (e.g., Ray, 1982). 
We consider the case where the production process takes place over time, and input choices $x$ are made before the stochastic shock $u$ is observed (e.g., inputs are chosen at the beginning of the growing season before weather conditions are known). Denote by $r \in \mathbb{R}_{++}^{n}$ the vector of prices for inputs $x$. Under the production function $z=g_{0}(K, u, y)$ where $y=f(x, t)$, and conditional on intermediate output $y$, a rational decision maker will always choose inputs $x$ so as to minimize cost $\operatorname{Min}_{x \in \mathbb{R}_{+}^{n}}\{\boldsymbol{r} \cdot \boldsymbol{x}: y=f(x, t)\}$. Note this result holds under general conditions as long as the decision maker has preferences that are nonsatiated in income. Indeed, it holds under production risk (represented here by the stochastic shock $u$ ), under output price risk, and under farmers' risk aversion. To see this, conditional on $y$, cost minimizing input choices would always stochastically dominate any other feasible input choice.

On that basis, conditional on $(\boldsymbol{r}, \boldsymbol{y}, \boldsymbol{t})$, our analysis proceeds assuming cost minimizing behavior where inputs $x$ are chosen as follows:

$$
C(\boldsymbol{r}, y, t)=r \cdot x^{c}(\boldsymbol{r}, y, t)=\operatorname{Min}_{x \in \mathbb{R}_{+}^{n}}\{r \cdot x: y=f(x, t)\},
$$

where $C(\boldsymbol{r}, y, \boldsymbol{t})$ is the indirect cost function, and $\boldsymbol{x}^{c}(\boldsymbol{r}, y, \boldsymbol{t})$ denotes the cost minimizing input demand functions. Conditional on intermediate output $y$, cost minimization in equation (1) holds because, under weak separability, the marginal rates of substitution among inputs $x$ are independent of the stochastic shocks $u$. In general, the cost function $C(r, y, t)$ in equation (1) is linear, homogeneous, and concave in prices $r$. When the cost function $C(\boldsymbol{r}, y, t)$ is differentiable, it satisfies Shephard's lemma, where $\frac{\partial C(\boldsymbol{r}, y, t)}{\partial r_{i}}=x_{i}^{c}(\boldsymbol{r}, \boldsymbol{y}, \boldsymbol{t}), i=$ $1, \ldots, n$. Shephard's lemma can be alternatively written as

$$
\frac{\partial \ln C(\boldsymbol{r}, y, \boldsymbol{t})}{\partial \ln \left(r_{i}\right)}=w_{i}^{c}(\boldsymbol{r}, y, \boldsymbol{t}),
$$

where $w_{i}(\boldsymbol{r}, \boldsymbol{y}, \boldsymbol{t})=\frac{r_{i} x_{i}^{c}(\boldsymbol{r}, y, \boldsymbol{t})}{C(\boldsymbol{r}, y, \boldsymbol{t})}$ is the cost share for the ith input. Our empirical analysis will rely on the specification and estimation of the cost function $C(r, y, t)$ given in equation (1) and the cost share equations $w_{i}^{c}(\boldsymbol{r}, y, \boldsymbol{t})$ given in equation (2).

The cost minimization problem in equation (1) has well-known implications for input demands (e.g., Chambers, 1988). From the Euler theorem, the linear homogeneity of $C(r, y, t)$ in $r$ implies the homogeneity conditions

$$
\sum_{i=1}^{n} \frac{\partial \ln C(\boldsymbol{r}, y, \boldsymbol{t})}{\partial \ln \left(r_{i}\right)}=1 .
$$

We are interested in evaluating the effects of input prices $r$, intermediate output $y$, and technology $t$ on input demand. First, the effects of prices can be measured by the price elasticities of input demands $\frac{\partial \ln \left(x_{i}^{c}\right)}{\partial \ln \left(r_{j}\right)}$ for $i, j=1, \ldots, n$. Following 
Berndt and Wood (1975), these demand elasticities satisfy

$$
\frac{\partial \ln \left(x_{i}^{c}\right)}{\partial \ln \left(r_{j}\right)}=-\delta_{i j}+w_{j}+\frac{\partial \ln \left(w_{i}\right)}{\partial \ln \left(r_{j}\right)},
$$

where $\delta_{i j}=\left\{\begin{array}{l}1 \\ 0\end{array}\right\}$ when $i\left\{\begin{array}{l}= \\ \neq\end{array}\right\} j$. Second, from Chambers (1988), economies of size evaluated at point $(\boldsymbol{r}, \boldsymbol{y}, \boldsymbol{t})$ can be written as

$$
E S(\boldsymbol{r}, y, \boldsymbol{t})=1 /\left[\frac{\partial \ln (C(\boldsymbol{r}, y, t))}{\partial \ln (y)}\right],
$$

where $E S(\boldsymbol{r}, y, \boldsymbol{t}) \stackrel{\overrightarrow{<}\}}{=} 1$ corresponds to $\left.\begin{array}{c}\text { increasing } \\ \text { constant } \\ \text { decreasing }\end{array}\right\}$ return to size in the neighborhood of $(\boldsymbol{r}, \boldsymbol{y}, \boldsymbol{t})$. Third, the rate of technological change evaluated at point $(\boldsymbol{r}, \boldsymbol{y}, \boldsymbol{t})$ can be written as

$$
R T C(\boldsymbol{r}, y, \boldsymbol{t})=-\frac{\partial \ln (C(\boldsymbol{r}, \boldsymbol{y}, \boldsymbol{t}))}{\partial \boldsymbol{t}} / \frac{\partial \ln (C(\boldsymbol{r}, \boldsymbol{y}, \boldsymbol{t}))}{\partial \ln (y)},
$$

where $R T C(\boldsymbol{r}, \boldsymbol{y}, \boldsymbol{t})$ measures the proportional change in output because of technological change in the neighborhood of $(\boldsymbol{r}, y, t)$. Finally, from Binswanger (1974), the nature of technological change can be expressed in terms of the bias in technological change

$$
B_{i}(\boldsymbol{r}, y, \boldsymbol{t})=\partial w_{i}(\boldsymbol{r}, y, \boldsymbol{t}) / \partial \boldsymbol{t}, i=1, \ldots, n .
$$

Technological change is said to be Hicks neutral when $B_{i}(\boldsymbol{r}, \boldsymbol{y}, \boldsymbol{t})=0$ for all $i$ and all $(\boldsymbol{r}, y, t)$. It is Hicks-biased toward the $i$ th factor (or $i$ th factor using) when $B_{i}(\boldsymbol{r}, \boldsymbol{y}, \boldsymbol{t})>0$, and it is Hicks-biased against the $i$ th factor (or $i$ th factor saving) when $B_{i}(\boldsymbol{r}, y, \boldsymbol{t})<0$. Thus, departures from Hicks-neutral technological change correspond to situations where technological change affects the cost share of some inputs. Such effects are relevant in the evaluation of the "induced innovation" hypothesis (e.g., Binswanger, 1974). Under induced innovations, technological change responds to relative scarcity: new technology would develop to reduce the demand for inputs that are becoming more expensive (i.e., leading to "input saving" bias) and to increase the demand for inputs that are becoming cheaper (i.e., leading to "input using" bias).

\section{An Application to U.S. Agriculture}

In this section, we apply the model discussed previously to U.S. agriculture using a translog cost specification. Our investigation involves six inputs: (1) labor, (2) energy, (3) fertilizer, (4) herbicides, (5) insecticides, and (6) other inputs. ${ }^{3}$ Given

3 In a preliminary analysis, we estimated a cost function including capital and conditional on final output. We found that the estimated cost function was not concave in prices, which is not consistent with cost minimization. As discussed in Section 2, we interpreted this result as evidence that production risk undermined the validity of cost minimization conditional on final output. 
our focus on biotechnology, we include three variables for technology: a time trend defined as $t=y e a r-2000$, which captures long-term technical change, and the variables $B t(t)$ and $H T(t)$, which measure biotechnology adoption at time $t$ ("insect resistance" for $B t(t)$ and "herbicide tolerance" for $H T(t)$ ). Thus, conditional on $(\boldsymbol{r}, y, t)$, we consider a translog specification for the cost function $C(\boldsymbol{r}, \boldsymbol{y}, \boldsymbol{t})$ of the form

$$
\begin{aligned}
& \ln [C(\boldsymbol{r}, y, t)]=a_{0}+\sum_{i=1}^{6} a_{i} \ln \left(r_{i}\right)+0.5 \sum_{i=1}^{6} \sum_{j=1}^{6} a_{i j} \ln \left(r_{i}\right) \ln \left(r_{j}\right)+\delta \ln (y) \\
& +b_{0} t+\sum_{i=1}^{6} b_{i} t \ln \left(r_{i}\right)+d_{0} B t(t)+\sum_{i=1}^{6} d_{i} B t(t) \ln \left(r_{i}\right) \\
& +e_{0} H T(t)+\sum_{i=1}^{6} e_{i} H T(t) \ln \left(r_{i}\right)+\epsilon_{0}
\end{aligned}
$$

where $(\boldsymbol{a}, \delta, \boldsymbol{b}, \boldsymbol{d}, \boldsymbol{e})$ are parameters, $\boldsymbol{a}=\left(a_{1}, a_{2}, \ldots, a_{6}\right), \boldsymbol{b}=\left(b_{1}, b_{2}, \ldots, b_{6}\right)$, $d=\left(d_{1}, d_{2}, \ldots, d_{6}\right)$, and $\boldsymbol{e}=\left(e_{1}, e_{2}, \ldots, e_{6}\right)$, satisfying the symmetry conditions $a_{i j}=a_{j i}$ for $i \neq j$, and $\epsilon_{0}$ is an error term with mean zero. The specification (equation $7 \mathrm{a}$ ) is flexible in the sense that it does not impose a priori restrictions on the elasticities of substitution among inputs (Diewert and Wales, 1987). The variables $B t(t)$ and $H T(t)$ in equation (7a) identify explicitly the role of biotechnology. From equation (5), the parameter $\delta$ captures returns to scale, with

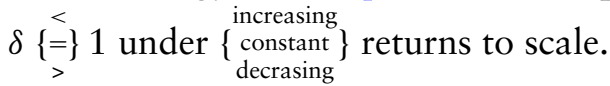

Using Shephard's lemma in equation (2), the cost share of the $i$ th factor associated with equation $(7 \mathrm{a})$ is

$$
w_{\mathrm{i}}(r, y, t)=a_{i}+\sum_{j=1}^{6} a_{i j} \ln \left(r_{j}\right)+b_{i} t+d_{i} B t(t)+e_{i} H T(t)+\epsilon_{i},
$$

where $\epsilon_{i}$ is an error term with mean zero, $E\left(\epsilon_{i}\right)=0$, and variance/covariance $E\left(\epsilon_{i} \cdot \epsilon_{j}\right)=\sigma_{i j}$ for $i, j=0, \ldots, 6$. Applied to equations $(7 \mathrm{a})$ and $(7 \mathrm{~b})$, the homogeneity restrictions in equation (3) are as follows: $\sum_{i=1}^{6} a_{i}=1, \sum_{i=1}^{6} a_{i j}=0$ for all $j$, and $\sum_{i=1}^{6} b_{i}=\sum_{i=1}^{n} d_{i}=\sum_{i=1}^{6} e_{i}=0$. Equations $(7 \mathrm{a})$ and $(7 \mathrm{~b})$ are a system of seven stochastic equations that can be estimated econometrically. Noting that $\sum_{i=1}^{6} w_{i}=1$ implies that knowing five cost shares is equivalent to knowing the sixth one. It means that we drop one share equation without a loss of information. When using maximum likelihood estimation, the econometric results are invariant to the equation dropped (Barten, 1969). On that basis, we proceed estimating six equations: the cost equation ( $7 \mathrm{a})$ along with five cost share equations in $(7 \mathrm{~b})$.

Our empirical analysis relies on farm input and output data reported by the USDA's Economic Research Service (ERS). We examine agricultural productivity in the United States in general and in the Corn Belt states because GM adoption is significantly concentrated in the staple crops such as corn and soybean. The 
investigation will evaluate the rate and nature of technological change and its implications for the structure of input demand. Our sample information involves annual data starting in 1960. At the U.S. level, the data cover the period 19602013. However, USDA-ERS stopped reporting state-level data after 2004. Thus, our state-level analysis covers the period 1960-2004. Our analysis focuses on nine states in the Corn Belt: Illinois (IL), Iowa (IA), Indiana (IN), Michigan (MI), Minnesota (MN), Missouri (MO), Nebraska (NE), Ohio (OH), and Wisconsin (WI). We chose the Corn Belt for two reasons: (1) corn and soybean are the two main crops in this region, and (2) corn and soybean are two of three crops (the third one being cotton) that have greatly benefited from biotechnology during the last two decades.

For each of the six inputs included in our analysis, a price index in each year (and in each state in the state-level analysis) was obtained from USDA (2017b). Input quantity indices were obtained by dividing input cost by the associated price indices. For labor, energy, and fertilizer, the price and quantity indices were obtained from Eldon Ball at USDA (2017b). For herbicides and insecticides, the input prices were obtained from Richard Nehring at ERS, following the hedonic procedure proposed by Fernandez-Cornejo and Jans (1995). For "other inputs," the price index and quantity index were calculated using a Fisher index applied to the remaining inputs (feed, seed, purchased services, and other intermediate inputs). Finally, the quantity of "intermediate output" $y$ was measured using a Fisher quantity index (Diewert, 1992). ${ }^{4}$ Summary statistics for the U.S. data are reported in Table 1.

The adoption rates $B t(t)$ and $H T(t)$, at both the U.S. level (for the U.S. analysis) and the state-level (for the Corn Belt analysis), were obtained from Fernandez-Cornejo et al. (2014), USDA (2017a), and the Dmrkynetec farm survey. ${ }^{5}$ Note that biotechnology started being adopted in 1995, thus covering 19 years in our U.S. sample (from 1995 to 2013). To make the parameters of the variables $t, B t(t)$, and $H T(t)$ comparable in equations (7a) and (7b), we define $B t(t)=[19 *$ (observed proportional adoption rate of $B t$ technology)] and $H T(t)=[19 *$ (observed proportional adoption rate of $H T$ technology)]. The parameters $d$ and $\boldsymbol{e}$ in equations (7a) and (7b) provide a basis to evaluate the effects of biotechnology adoption on U.S. agriculture, with separate effects for Bt technology and HT technology. Bt can be viewed as an insecticide

4 Consider a situation with $k$ quantities $q \in \mathbb{R}^{k}$ and $k$ corresponding prices $p \in \mathbb{R}^{k}$. For given reference prices $p_{0} \in \mathbb{R}^{k}$ and reference quantities $q_{0} \in \mathbb{R}^{k}$, the Fisher price index is $P=\sqrt{\frac{p \cdot q_{0}}{p_{0} \cdot q_{0}} \frac{p \cdot q}{p_{0} \cdot q}}$, and the Fisher quantity index is $Q=\sqrt{\frac{p_{0} \cdot q}{p_{0} \cdot q_{0}} \frac{p \cdot q}{p \cdot q_{0}}}$ (Diewert, 1992). We took $p_{0}$ and $q_{0}$ as sample means for the corresponding variables. Using netput notation, the Fisher index for "intermediate output" was obtained using $p \cdot q=p_{a} q_{a}-\sum_{i=1}^{n} p_{i} x_{i}$, where $q_{a}$ is output, $x_{i}$ is the $i$ th input, and capital is excluded from the list of $n$ inputs.

5 Dmrkynetec changed its name to GfK Kynetec in May 1999. The company is based in St. Louis, Missouri, and has become a leading agricultural marketing and consulting firm globally. 
Table 1. Summary Statistics for U.S. Agriculture

\begin{tabular}{lllll}
\hline \hline Variables & Mean & Minimum & Median & Maximum \\
\hline Intermediate output index & 1.002 & 0.479 & 0.945 & 1.770 \\
Labor quantity index & 90,177 & 57,795 & 82,036 & 155,145 \\
Labor price index & 0.488 & 0.060 & 0.325 & 1.343 \\
Energy quantity index & 14,906 & 12,724 & 14,506 & 19,540 \\
Energy price index & 0.559 & 0.131 & 0.541 & 1.598 \\
Fertilizer quantity index & 13,887 & 8,103 & 14,231 & 21,108 \\
Fertilizer price index & 0.636 & 0.158 & 0.523 & 1.935 \\
Herbicide quantity index & 2,851 & 215 & 3,032 & 6,554 \\
Herbicide price index & 0.731 & 0.302 & 0.711 & 1.296 \\
Insecticide quantity index & 2,820 & 772 & 2,005 & 9,877 \\
Insecticide price index & 0.942 & 0.203 & 1.021 & 1.828 \\
Other input quantity index & 67,333 & 49,193 & 68,230 & 86,314 \\
Other input price index & 1.001 & 0.317 & 1.023 & 2.335 \\
\hline \hline
\end{tabular}

Note: Number of observations $=54$.

substitute. HT can be viewed as an herbicide complement for the corresponding herbicide product but a substitute for other herbicides (e.g., Fernandez-Cornejo et al., 2012). Note that our analysis is applied to agriculture as a whole. It captures productivity effects that are specific to each crop as well as effects that occur across agricultural activities. The latter effects include the effects of crop rotation and of crop-livestock interactions. Although most previous analyses of biotechnology have been crop specific (e.g., Bustos, Caprettini and Ponticelli, 2016; Carpenter, 2010; Klümper and Qaim, 2014; Perry, Moschini, and Hennessy, 2016), our analysis includes the productivity effects of input use and covers a broader scope of agriculture across all production activities. In this context, we examine the effects of HT and Bt technology on farm productivity and on input use, especially on the demand for herbicide and insecticides separately.

\section{Econometric Estimates}

In a preliminary analysis of the data, we investigated the nature of returns to scale. As noted previously, constant returns to scale (CRS) corresponds to $\delta=1$ in equation (7a). We tested the null hypothesis of CRS $\left(\mathrm{H}_{0}: \delta=1\right)$ using both U.S. aggregate data and state-level Corn Belt data. We estimated the model by the generalized method of moments using $\ln \left(y_{t-1}\right)$ as instrument for $\ln \left(y_{t}\right)$. In this context, we failed to reject the null hypothesis at the $9 \%$ significance level with U.S. data and at the $70 \%$ significance level using state-level Corn Belt data. Thus, we did not find statistical evidence against CRS. On that basis, the analysis presented subsequently was conducted imposing CRS with $\delta=1$ in equation (7a). In addition, note that CRS offers a significant advantage for our 
empirical investigation: under CRS, there is no parameter associated with output $y$ in equations (7a) and (7b). It means that the presence of measurement errors in $y$ only affects the estimated variance of the error term in equation (7a), and it has no effect on the remaining parameter estimates. In other words, the estimation of all parameters in equations (7a) and (7b) are robust to the mismeasurement of intermediate output $y .{ }^{6}$ This feature is important in agriculture as production uncertainty makes the measurement of output somewhat problematic (e.g., Chavas, 2008; Pope and Chavas, 1994).

Assuming $\delta=1$, the translog model given in equations (7a) and (7b) constitutes a system of equations. Allowing for different variances and nonzero covariances across equations, the system was estimated by maximum likelihood (after imposing the homogeneity and symmetry restrictions discussed previously). To explore possible serial correlation, we allowed the error terms $\epsilon$ in equations (7a) and (7b) to exhibit first-order serial correlation, where $\epsilon_{i t}=\rho_{i} \epsilon_{i, t-1}$, and $\rho_{i}$ is the serial correlation coefficient for the $i$ th equation, $i=0, \ldots, 5$. The analysis was applied to the U.S.-level data over the period 1960-2013 and to the state-level data from the Corn Belt over the period 1960-2004. For the statelevel analysis, the estimation was pooled across states, with state dummies being added to each equation to capture possible heterogeneity across Corn Belt states. The state dummies were introduced to be as intercept shifters in the cost equation (7a) and the cost share equation (7b), reflecting possible differences in technology across states, and they were introduced as interaction effects with the time trend variable $t$ in the cost equation (7a), capturing possible differences in productivity growth across states. ${ }^{7}$

The econometric results are reported in Table 2, where the subscript stands for the corresponding input: " 1 " for labor, " 2 " for energy, " 3 " for fertilizer, " 4 " for herbicides, " 5 " for insecticides, and " 6 " for other inputs.

Table 2 shows that many estimated parameters are statistically significant. As reflected by the coefficients $a$, input prices have significant effects on input demands. Also, most of the time trend parameters $\boldsymbol{b}$ are statistically significant, indicating the presence of important technological change in U.S. agriculture during the last 50 years. In addition, several of the $d$ and $e$ parameters are statistically significant, indicating that biotechnology is among the important

6 Note that this robustness disappears under any departure from CRS. Indeed, without CRS (or more generally under nonhomothetic technology), measurement errors in $y$ create endogeneity problems and identification issues that can be difficult to resolve (e.g., Tack et al., 2015). Without CRS, endogeneity issues would arise from the correlation between $y$ and the error term in equation (7a), implying that least squares would generate biased and inconsistent parameter estimates. Such issues raise questions about the validity of some previous cost-based empirical analyses of agriculture (e.g., Antle, 1984; Lopez, 1982; Ray, 1982).

7 We did consider estimating the model taking into consideration the spatial autocorrelation for the Corn Belt model. However, this was problematic because of our small sample size: having only 44 observations to estimate covariances across six equations and nine states generates a singular estimated variance-covariance matrix. 
Table 2. Parameter Estimates of the Translog Cost Function in Equations (7a) and (7b)

\begin{tabular}{|c|c|c|c|c|c|}
\hline \multirow[b]{2}{*}{ Parameters } & & \multicolumn{2}{|c|}{ United States } & \multicolumn{2}{|c|}{$\begin{array}{l}\text { Corn Belt States } \\
\text { (benchmark Iowa) }\end{array}$} \\
\hline & & Estimate & $\begin{array}{l}\text { Standard } \\
\text { Error }\end{array}$ & Estimate & $\begin{array}{l}\text { Standard } \\
\text { Error }\end{array}$ \\
\hline \multirow[t]{7}{*}{ Intercept } & $\mathrm{a} 0$ & $0.053^{\text {** }}$ & 0.021 & 0.042 & 0.051 \\
\hline & a1 & $0.326^{* * *}$ & 0.013 & $0.321^{* * *}$ & 0.013 \\
\hline & $\mathrm{a} 2$ & $0.081^{* * *}$ & 0.005 & $0.055^{* * *}$ & 0.003 \\
\hline & a3 & $0.073^{* * *}$ & 0.008 & $0.069^{* * *}$ & 0.004 \\
\hline & $\mathrm{a} 4$ & $0.028^{* * *}$ & 0.003 & $0.022^{* * *}$ & 0.004 \\
\hline & a5 & $0.027^{* * *}$ & 0.004 & $0.003^{* * *}$ & 0.001 \\
\hline & $\mathrm{a} 6$ & $0.465^{* * *}$ & 0.013 & $0.530^{* * *}$ & 0.013 \\
\hline \multirow{21}{*}{$\begin{array}{l}\text { Coefficients of } \\
\log \text { (input prices) }\end{array}$} & a11 & $0.143^{* * *}$ & 0.019 & $0.171^{* * *}$ & 0.005 \\
\hline & a22 & $0.043^{* * *}$ & 0.004 & $0.041^{* * *}$ & 0.002 \\
\hline & a33 & $0.016^{* *}$ & 0.007 & $0.020^{* * *}$ & 0.003 \\
\hline & $\mathrm{a} 44$ & 0.003 & 0.002 & $0.008^{* * *}$ & 0.001 \\
\hline & a55 & -0.0004 & 0.003 & $0.0005^{*}$ & 0.0003 \\
\hline & $\mathrm{a} 66$ & $0.164^{* * *}$ & 0.017 & $0.158^{*}$ & 0.008 \\
\hline & $\mathrm{a} 12$ & $-0.012^{* *}$ & 0.005 & $-0.014^{* * *}$ & 0.001 \\
\hline & a13 & $-0.016^{*}$ & 0.009 & $-0.022^{* * *}$ & 0.002 \\
\hline & a14 & 0.005 & 0.004 & $-0.009^{* * *}$ & 0.001 \\
\hline & a15 & -0.006 & 0.004 & $-0.001^{* * *}$ & 0.0003 \\
\hline & a16 & $-0.114^{* * *}$ & 0.014 & $-0.126^{* * *}$ & 0.005 \\
\hline & $\mathrm{a} 23$ & 0.004 & 0.003 & $0.005^{* * *}$ & 0.001 \\
\hline & $\mathrm{a} 24$ & $-0.006^{* * *}$ & 0.002 & 0.0001 & 0.001 \\
\hline & a25 & $0.006^{* * *}$ & 0.002 & 0.001 & 0.0004 \\
\hline & a26 & $-0.035^{* * *}$ & 0.006 & -0.032 & 0.002 \\
\hline & a34 & 0.002 & 0.002 & -0.0004 & 0.001 \\
\hline & a35 & -0.003 & 0.003 & $-0.001^{*}$ & 0.0004 \\
\hline & a36 & -0.003 & 0.008 & $-0.002^{*}$ & 0.004 \\
\hline & a45 & $0.005^{* * * *}$ & 0.002 & 0.0002 & 0.0004 \\
\hline & a46 & $-0.011^{* * *}$ & 0.004 & 0.001 & 0.002 \\
\hline & a56 & -0.001 & 0.005 & 0.001 & 0.001 \\
\hline \multirow[t]{7}{*}{ t coefficients } & b0 & $-0.031^{* * *}$ & 0.001 & $-0.026^{* * *}$ & 0.002 \\
\hline & b1 & $0.005^{* * * *}$ & 0.001 & $-0.005^{* * *}$ & 0.0003 \\
\hline & b2 & -0.0001 & 0.0002 & $0.0004^{* * *}$ & 0.0001 \\
\hline & b3 & $0.001^{\text {** }}$ & 0.0003 & $0.001^{* * * *}$ & 0.0001 \\
\hline & b4 & $0.0004^{* * *}$ & 0.0001 & $0.001^{* * * *}$ & 0.0001 \\
\hline & b5 & $0.001^{* * * *}$ & 0.0001 & $0.0001^{* * *}$ & 0.0000 \\
\hline & b6 & 0.003 & 0.0004 & $0.002^{* * *}$ & 0.0003 \\
\hline \multirow[t]{7}{*}{ Bt coefficients } & $\mathrm{d} 0$ & 0.015 & 0.014 & 0.006 & 0.013 \\
\hline & $\mathrm{d} 1$ & -0.005 & 0.005 & -0.002 & 0.002 \\
\hline & $\mathrm{d} 2$ & 0.001 & 0.001 & 0.0004 & 0.0004 \\
\hline & $\mathrm{d} 3$ & $0.005^{*}$ & 0.003 & $0.002^{*}$ & 0.001 \\
\hline & $\mathrm{d} 4$ & 0.001 & 0.001 & $-0.001^{*}$ & 0.0004 \\
\hline & $\mathrm{d} 5$ & 0.001 & 0.001 & 0.0001 & 0.0001 \\
\hline & $\mathrm{d} 6$ & -0.003 & 0.004 & 0.001 & 0.002 \\
\hline
\end{tabular}


Table 2. Continued

\begin{tabular}{|c|c|c|c|c|c|}
\hline \multirow[b]{2}{*}{ Parameters } & & \multicolumn{2}{|c|}{ United States } & \multicolumn{2}{|c|}{$\begin{array}{l}\text { Corn Belt States } \\
\text { (benchmark Iowa) }\end{array}$} \\
\hline & & Estimate & $\begin{array}{l}\text { Standard } \\
\text { Error }\end{array}$ & Estimate & $\begin{array}{l}\text { Standard } \\
\text { Error }\end{array}$ \\
\hline \multirow[t]{7}{*}{ HT coefficients } & $\mathrm{e} 0$ & 0.003 & 0.012 & -0.010 & 0.009 \\
\hline & e1 & 0.007 & 0.004 & 0.001 & 0.002 \\
\hline & e2 & -0.001 & 0.001 & $-0.001^{* *}$ & 0.0003 \\
\hline & e3 & $-0.004^{*}$ & 0.002 & $-0.001^{*}$ & 0.001 \\
\hline & $\mathrm{e} 4$ & $-0.002^{* *}$ & 0.001 & $-0.001^{* *}$ & 0.0003 \\
\hline & e5 & -0.001 & 0.001 & 0.0001 & 0.0001 \\
\hline & e6 & 0.001 & 0.003 & 0.001 & 0.002 \\
\hline \multirow{6}{*}{$\begin{array}{l}\text { Serial correlation } \\
\text { coefficients }\end{array}$} & $\rho_{0}$ & -0.030 & 0.140 & $0.271^{* * *}$ & 0.049 \\
\hline & $\rho_{1}$ & 0.217 & 0.138 & $0.724^{* * *}$ & 0.034 \\
\hline & $\rho_{2}$ & 0.171 & 0.137 & $0.580^{* * *}$ & 0.042 \\
\hline & $\rho_{3}$ & $0.508^{* * *}$ & 0.117 & $0.659^{* * *}$ & 0.036 \\
\hline & $\rho_{4}$ & $0.446^{* * *}$ & 0.124 & $0.871^{* * *}$ & 0.025 \\
\hline & $\rho_{5}$ & $0.246^{*}$ & 0.138 & $0.676^{* * *}$ & 0.039 \\
\hline
\end{tabular}

Notes: The number of observations is 54 (covering the period 1960-2013) for the United States and 396 $(=44 \times 9$ states, covering the period 1960-2003) for the Corn Belt states. The estimates are based on the maximum likelihood estimation of the cost function (7a) and the cost share (7b) equations with six inputs: 1 , labor; 2 , energy; 3 , fertilizer; 4 , herbicide; 5 , insecticide; 6 , other inputs. $\rho_{i}$ is the first-order serial correlation coefficient for $\epsilon_{i}$ in equations (7a) and (7b). The asterisks (***, ${ }^{* *}$, and ${ }^{*}$ ) indicate significance at the $1 \%, 5 \%$, and $10 \%$ levels, respectively. Although not reported in the table, parameters for state dummy variables were also estimated for the Corn Belt states, allowing for differences in technology and in productivity growth across states. Bt, Bacillus thuringiensis; HT, herbicide tolerance.

factors affecting technological change. The exact nature of these effects is further examined subsequently. Finally, in our state-level analysis, many of the state dummy variables (not reported in Table 2) were also found to be statistically significant (see Table 3). ${ }^{8}$

As discussed in Section 2, the cost function $C(r, y, t)$ is concave in prices $r$. We investigated whether the estimates reported in Table 2 satisfy this property. The concavity of $C(r,$.$) means that the matrix \partial^{2} C / \partial \mathbf{r}^{2}$ is negative semidefinite, all its eigenvalues being nonpositive. We evaluated the eigenvalues of $\partial^{2} \mathrm{C} / \partial \mathbf{r}^{2}$ at all data points in our U.S. sample. We found that all eigenvalues were not always less than or equal to zero. Based on the estimated distribution of the parameters reported in Table 2, we used Monte Carlo simulation to simulate the distribution of the eigenvalues at each data point. Using these simulated distributions, we tested the hypothesis that all eigenvalues are nonpositive. We found that, when positive, the eigenvalues were not statistically different from zero at the $10 \%$

8 We also conducted the analysis of Corn Belt states for each state separately. The econometric estimates showed additional evidence of heterogeneity across states. The results are available from the authors upon request. 
Table 3. Hypothesis Testing

\begin{tabular}{lcc}
\hline \hline Wald tests & United States & Corn Belt states \\
\hline No technological change & & \\
Wald test statistic & $2,223.4$ & 861.2 \\
$P$ value & 0.0001 & 0.0001 \\
Hicks neutral technological change & 274.4 & 750.4 \\
Wald test statistic & 0.0001 & 0.0001 \\
$P$ value & & $1,843.5$ \\
Testing for identical productivity across states & - & 0.0001 \\
Wald test statistic & & 17.76 \\
$P$ value & - & 0.023 \\
Testing for identical productivity growth across states & & \\
Wald test statistic & & \\
$P$ value & & \\
\hline \hline
\end{tabular}

significance level. On that basis, we conclude that, in our U.S. sample, there is no strong statistical evidence against the concavity of the estimated cost function.

To support our analysis of the effects of technological change, we conducted several formal tests. The test results are reported in Table 3. First, we tested the hypothesis of no technological change. It corresponds to the null hypothesis that all parameters $b, d$, and $\boldsymbol{e}$ are jointly zero. Using a Wald test, Table 3 provides strong evidence against this null hypothesis both at the national level and at the state level (with $P$ values less than 0.01 ), which confirms a large impact of technological change on U.S. agriculture. Next, we investigated the nature of technological change. We tested whether technological change was "Hicks neutral" (i.e., whether it would not affect the input cost shares). From equation (6b), Hicks neutral technological change corresponds to the parameters $\left(b_{i}, d_{i}, e_{i}\right)$ for factor $i$ being all zero for all $i=1, \ldots, 6$. Using a Wald test, Table 3 shows that Hicks neutral technological change is strongly rejected for all factors both at the national level and the state level (with $P$ values less than 0.01). Thus, consistent with previous research (e.g., Binswanger, 1974), we find strong evidence that technological change is "Hicks biased" and has significant effects on input cost shares. The exact nature of this bias is further discussed subsequently. Finally, in the state-level analysis, we examined possible heterogeneity in productivity across states. This involved testing the null hypothesis that all coefficients associated with the state dummy variables (as cost shifters, as cost share shifters, and as interactions with time trend) are zero. As reported in Table 3, we strongly reject this null hypothesis (with a $P$ value less than 0.01), indicating the presence of much heterogeneity in agricultural productivity across states in the Corn Belt. This is consistent with the results obtained by Lusk, Tack, and Hendricks (2017). We also investigated whether productivity growth was similar across states. This was done by testing the null hypothesis that the coefficients of interaction variables between the state 
Table 4. Rate of Technological Change (annual percentage)

\begin{tabular}{lllllllllllll}
\hline \hline & & \multicolumn{10}{c}{ Corn Belt States } \\
\cline { 3 - 12 } Period & United States & Average & IA & IL & IN & MI & MN & MO & NE & OH & WI \\
\hline $1960 \mathrm{~s}$ & 2.46 & 2.46 & 1.92 & 3.19 & 2.60 & 2.82 & 1.23 & 3.34 & 2.56 & 2.52 & 1.91 \\
$1970 \mathrm{~s}$ & 2.54 & 2.51 & 1.97 & 3.24 & 2.65 & 2.87 & 1.33 & 3.41 & 2.60 & 2.57 & 1.96 \\
$1980 \mathrm{~s}$ & 2.60 & 2.52 & 1.98 & 3.25 & 2.66 & 2.87 & 1.34 & 3.42 & 2.61 & 2.58 & 1.96 \\
$1990 \mathrm{~s}$ & 2.50 & 2.95 & 2.41 & 3.68 & 3.09 & 3.31 & 1.77 & 3.85 & 3.04 & 3.01 & 2.34 \\
$2000 \mathrm{~s}$ & 1.29 & 3.12 & 2.58 & 3.85 & 3.26 & 3.48 & 1.94 & 4.02 & 3.21 & 3.18 & 2.56 \\
Pre-1995 & 2.57 & 2.53 & 1.97 & 3.26 & 2.67 & 2.89 & 1.35 & 3.43 & 2.62 & 2.59 & 1.97 \\
Post-1995 & 1.65 & 2.96 & 2.42 & 3.69 & 3.10 & 3.32 & 1.79 & 3.86 & 3.05 & 3.02 & 2.41 \\
\hline \hline
\end{tabular}

Note: The analysis is based on 54 years of data (covering the period 1960-2013) for the United States and 44 years of data (covering the period 1960-2003) for the Corn Belt states.

dummies and time trend are zero. As reported in Table 3, we rejected this null hypothesis at the 0.023 significance level, providing evidence of heterogeneity in productivity growth across states in the Corn Belt. The differences in productivity growth across states are reported in Table 4 and discussed subsequently.

\section{Economic Implications}

The estimates of equations $(7 \mathrm{a})$ and $(7 \mathrm{~b})$ reported in Table 2 provide all the information necessary to evaluate agricultural technology and farm input demands. First, the rate of technological change $(R T C)$ can be obtained from equation (6a). The estimated $R T C$ (measured in annual percentage) is reported in Table 4 for selected periods. Table 4 shows that U.S. agriculture has exhibited rapid technological progress over the last few decades. The RTC goes from $1.29 \%$ to $2.60 \%$. These results can be compared with previous USDA estimates of RTC obtained by Ball et al. (1997), Ball, Hallahan, and Nehring (2004), and Wang et al. (2015). All estimates reflect rapid productivity growth in agriculture. Our pre-1995 RTC estimate is 2.57 ; it is broadly consistent with the estimate of 2.65 reported by Ball et al. (1997) for the period 1960-1994. ${ }^{9}$ Table 4 reports that, at the U.S. level, RTC declines from 2.57 before 1995 to 1.65 after 1995. This pattern indicates some slowdown of technological progress in U.S. agriculture. Again, this result is consistent with previous evidence (e.g., Wang et al., 2015).

However, our results differ in the Corn Belt. Table 4 reports $R T C$ for each of the nine Corn Belt states as well as the average RTC for the Corn Belt. It shows that Illinois exhibits a high $R T C$ varying from 3.19 in the 1960 s to 3.85 in the

9 Note that Wang et al. (2015) reports a lower RTC estimate of $1.7 \%$ for U.S. agriculture over the period 1960-1990. 
2000s. In contrast, Minnesota has an RTC going from 1.23 in the 1960s to 1.94 in the 2000s. This documents significant heterogeneity in productivity growth among Corn Belt states. The average $R T C$ was 2.53 in the Corn Belt before 1995, but that number has increased to 2.96 after 1995 . Thus, on average, the Corn Belt had a slightly lower productivity growth than the United States before 1995, but its productivity growth has increased since 1995 and is now ahead of the rest of United States. Since the year 1995 marks the start of the biotechnology revolution (i.e., the inception of GM commercial crops in U.S. agriculture), our analysis shows that the Corn Belt has benefited from biotechnology, and it has benefited more than the rest of the United States. This observation is not surprising: adoption of biotechnology has been rapid for corn and soybean (Fernandez-Cornejo et al., 2014), and corn and soybean are the two major crops grown in the Corn Belt. This result indicates that biotechnology has been a major driving factor of agricultural productivity in the United States. It also indicates that other U.S. regions (besides the Corn Belt) have not benefited as much from biotechnology, thus resulting in some slowdown in agricultural productivity growth. This slowdown is of some concern. Declining productivity growth may make it more difficult to feed a growing world population. A scenario where population grows faster than farm productivity would be associated with increased food insecurity and rising food prices. Such arguments stress the importance of research and development (both private and public) as key drivers of future agricultural productivity.

Second, our analysis allowed us to estimate the bias in technological change. The bias is given by the term $B_{i}=\partial w_{i} / \partial t$ in equation (6b), where technological change is said to be the ith factor-using if $B_{i}>0$ and the ith factor-saving if $B_{i}<0$. Before 1995 and from equation (7b), we have $B_{i}=b_{i}$. The coefficients $d_{i}$ and $e_{i}$ capture the changes in bias since 1995 because of the adoption of $\mathrm{Bt}$ and HT technology, respectively. As reported in Table 3, we found strong statistical evidence of bias in technological change. Recall that we consider six inputs: (1) labor, (2) energy, (3) fertilizer, (4) herbicides, (5) insecticides, and (6) other inputs. For both the U.S. and the Corn Belt results, Table 2 shows strong evidence that technological change has been labor saving (as $b_{1}$ is negative and statistically significant) and fertilizer using, herbicide using, and insecticide using (as the corresponding $b_{i}$ values are positive and significant). In addition, Table 2 shows evidence of bias in favor of energy for Corn Belt states. These results are largely consistent with previous research (e.g., Binswanger, 1974).

Table 2 also reports the biases related to biotechnology, including evaluations of Bt technology (as captured by the parameters $d$ ) and HT technology (as captured by the parameters $e$ ). Such parameters measure the change in biases beyond the ones captured by the parameters $\boldsymbol{b}$. From Table 2, the parameters $d_{1}$ and $e_{1}$ are not statistically different from zero, indicating that neither Bt nor HT technology has affected the labor-saving bias of technological change in U.S. agriculture. This result differs from Bustos, Caprettini, and Ponticelli (2016) 
who argued that HT technology contributed to labor-saving bias in Brazilian agriculture.

In addition, Table 2 reports that $b_{5}$ and $e_{5}$ are not statistically significant, indicating that neither Bt nor HT has affected the strong bias in favor of insecticide use that prevailed before 1995. Although previous literature has argued that biotechnology has contributed to a reduction in pesticide use (e.g., Klümper and Qaim, 2014), our analysis indicates that this result applies to herbicide (as discussed subsequently), but not to insecticide: neither Bt nor HT have reduced the bias toward insecticide use in U.S. agriculture. This likely reflects the fact that the insects targeted by Bt technology (e.g., the European corn borer and rootworms for corn) are not easily controlled using traditional insecticides.

For both the United States and the Corn Belt states, the parameter $d_{3}$ is found to be positive and statistically significant at the $10 \%$ level, indicating that Bt technology has increased the bias in favor of fertilizer use. This finding is important: by improving pest control, Bt technology helps reduce pest damages, making it easier for the plant to benefit from fertilizer applications.

For both the United States and the Corn Belt states, the parameters $e_{3}$ and $e_{4}$ are negative and statistically significant at the $10 \%$ level, providing evidence that HT technology has reduced the input-using bias for fertilizer and herbicide. Having $b_{3}>0, e_{3}<0$, and $b_{3}+e_{3}>0$ indicates that this bias in favor of using fertilizer was reduced but not eliminated by HT. For herbicide use at the U.S. level, we have $b_{4}>0, e_{4}<0$, and $b_{4}+e_{4}<0$, implying that HT was associated with a switch in technological change bias from herbicide using before 1995 to herbicide saving after 1995. This is another important finding: HT technology behaves as a substitute for herbicide use. Note that this finding is consistent with the results obtained by Fernandez-Cornejo et al. (2012) and Klümper and Qaim (2014). ${ }^{10}$ To the extent that reducing herbicide use is seen as being desirable from an environmental viewpoint, it indicates that, beyond improving weed control and reducing yield loss from weed infestation, biotechnology can generate environmental benefits. Yet, the patterns differ for the Corn Belt states, where we find that $b_{4}>0, e_{4}<0$, and $b_{4}+e_{4}>0$. Thus, in the Corn Belt states, HT technology reduces the bias in favor of using herbicide but does not eliminate it, indicating weaker substitution between HT and pesticide use. This reflects apparent regional heterogeneity in the effects of biotechnology on agriculture.

Another difference between the United States and Corn Belt results involves energy use. For the United States, the estimates of $b_{2}, d_{2}$, or $e_{2}$ are not statistically significant, indicating no bias in technical change with respect to energy use. However, the estimates differ for the Corn Belt where $b_{2}$ and $e_{2}$ are statistically

10 Although our analysis indicates that HT technology has been "herbicide saving” in the United States after 1995, it remains to see whether this effect will hold in the future. Indeed, the slow development of Roundup-resistant weeds indicates that such effects may not persist in the longer term. 
Table 5. Price Elasticities of Input Demand: U.S. Level, Evaluated at Sample Means

\begin{tabular}{lcccccc}
\hline \hline Price Quantity & Labor & Energy & Fertilizer & Herbicide & Insecticide & Other inputs \\
\hline Labor & $-0.208^{* *}$ & 0.018 & 0.009 & $0.035^{* *}$ & -0.004 & $0.149^{* * *}$ \\
& $(0.067)$ & $(0.019)$ & $(0.032)$ & $(0.014)$ & $(0.014)$ & $(0.049)$ \\
Energy & 0.083 & $-0.236^{* * *}$ & $0.128^{* *}$ & $-0.076^{* *}$ & $0.115^{* * *}$ & -0.014 \\
& $(0.086)$ & $(0.056)$ & $(0.056)$ & $(0.032)$ & $(0.036)$ & $(0.096)$ \\
Fertilizer & 0.040 & $0.118^{* *}$ & $-0.700^{* * *}$ & 0.053 & -0.029 & $0.517^{* * *}$ \\
& $(0.136)$ & $(0.052)$ & $(0.106)$ & $(0.032)$ & $(0.039)$ & $(0.123)$ \\
Herbicide & $0.601^{* *}$ & $-0.286^{* *}$ & 0.215 & $-0.776^{* * *}$ & $0.345^{* * *}$ & -0.099 \\
& $(0.234)$ & $(0.122)$ & $(0.133)$ & $(0.149)$ & $(0.119)$ & $(0.224)$ \\
Insecticide & -0.056 & $0.371^{* * *}$ & -0.100 & $0.297^{* * *}$ & $-1.008^{* * *}$ & $0.496^{* *}$ \\
& $(0.206)$ & $(0.118)$ & $(0.138)$ & $(0.102)$ & $(0.145)$ & $(0.238)$ \\
Other inputs & $0.075^{* * *}$ & -0.002 & $0.062^{* * *}$ & -0.003 & $0.017^{* *}$ & $-0.149^{* * *}$ \\
& $(0.024)$ & $(0.011)$ & $(0.015)$ & $(0.007)$ & $(0.008)$ & $(0.031)$ \\
\hline \hline
\end{tabular}

Notes: Standard errors are presented in parentheses below the elasticity estimates. The asterisks $\left({ }^{* * *},{ }^{* *}\right.$, and ${ }^{*}$ ) indicate significance at the $1 \%, 5 \%$, and $10 \%$ levels, respectively.

Table 6. Evolution of Own Price Elasticities for Selected Inputs: U.S. Level

\begin{tabular}{|c|c|c|c|c|c|c|}
\hline Period & Input & Energy & Fertilizer & Herbicide & Insecticide & Other inputs \\
\hline 1970s & & $\begin{array}{r}-0.03 \\
(0.01)\end{array}$ & $\begin{array}{c}-0.95 \\
(0.14)\end{array}$ & $\begin{array}{c}-1.55 \\
(0.30)\end{array}$ & $\begin{array}{c}-2.74 \\
(0.39)\end{array}$ & $\begin{array}{c}-0.14 \\
(0.03)\end{array}$ \\
\hline 1980s & & $\begin{array}{c}-0.32 \\
(0.08)\end{array}$ & $\begin{array}{r}-0.86 \\
(0.13)\end{array}$ & $\begin{array}{r}-1.17 \\
(0.22)\end{array}$ & $\begin{array}{r}-1.64 \\
(0.23)\end{array}$ & $\begin{array}{c}-0.14 \\
(0.03)\end{array}$ \\
\hline 1990s & & $\begin{array}{r}-0.17 \\
(0.04)\end{array}$ & $\begin{array}{c}-0.74 \\
(0.11)\end{array}$ & $\begin{array}{c}-0.94 \\
(0.18)\end{array}$ & $\begin{array}{c}-1.19 \\
(0.17)\end{array}$ & $\begin{array}{c}-0.15 \\
(0.03)\end{array}$ \\
\hline 2000s & & $\begin{array}{r}-0.16 \\
(0.04)\end{array}$ & $\begin{array}{r}-0.17 \\
(0.03)\end{array}$ & $\begin{array}{r}-0.26 \\
(0.05)\end{array}$ & $\begin{array}{r}-0.76 \\
(0.11)\end{array}$ & $\begin{array}{r}-0.16 \\
(0.03)\end{array}$ \\
\hline
\end{tabular}

Note: Standard errors are presented in parentheses below the elasticity estimates.

significant at the $5 \%$ level, with $b_{2}>0, e_{2}<0$, and $b_{2}+e_{2}<0$ implying a switch in biased technical change from energy using before 1995 to energy saving after 1995. This result likely reflects the fact that HT technology has been associated with reduced tillage (Fernandez-Cornejo et al., 2012; Perry, Moschini, and Hennessy, 2016).

Next, we evaluate the price elasticities of input demand. These estimates are obtained from equation (4) and reported in Tables 5 and 6. For the United States, Table 5 shows the own-price and cross-price elasticities for input demand evaluated at sample means. The own-price elasticities vary from -0.149 for "other inputs" to -1.008 for insecticides. With the exception of insecticides, all input demands are price inelastic. The results show that labor, energy, and other inputs have highly inelastic demands (with elasticities between -0.15 and $-0.25)$. Demand for fertilizer and herbicides are also inelastic but are relatively 
more price sensitive (all around -0.75 ). The cross-price elasticities tend to be positive, indicating that most inputs are substitutes. ${ }^{11}$ The cross-price elasticities are 0.345 for herbicide demand with respect to insecticide price and 0.371 for insecticide demand with respect to energy price, both being statistically significant.

Finally, Table 6 reports the evolution of own-price elasticities over time for the United States. Table 6 shows that the own-price elasticity for other inputs is fairly constant over time. It also reveals that the demands for fertilizer, herbicide, and insecticide are becoming much more price-inelastic over time. For example, the demand elasticity for fertilizer changed from -0.95 in the $1970 \mathrm{~s}$ to -0.74 in the 1990 s and to -0.17 in the 2000 s. This increased inelasticity of demand implies that farmers are becoming less responsive to prices for fertilizer, herbicide, and insecticide. Note that biotechnology has contributed to reducing the adverse effects of pest and weed damages. If pest and weed damages reduce the farmers' incentive to use fertilizers, then the adoption of biotechnology would be associated with stronger incentives to use fertilizers. Our results indicate that such changing incentives are associated with less demand sensitivity to input prices for fertilizer, herbicide, and insecticide. In other words, although U.S. farmers have benefited from rapid technological progress, their input choices have now become less sensitive to changing market conditions.

\section{Conclusion}

This article has explored the effects of biotechnology on farm productivity and input demands, with an application to U.S. agriculture. The analysis relies on a cost specification involving six inputs (labor, energy, fertilizer, herbicide, insecticide, and other inputs) and evaluating output as "intermediate output." We argue that focusing on intermediate output helps validate cost minimization in the presence of production uncertainty. Also, the distinction between herbicide and insecticide is relevant as it allows us to evaluate the separate effects of two aspects of GM technology: Bt technology (targeted to improving pest control) and HT technology (targeted to improving weed control).

Our empirical analysis is applied to two agricultural data sets: U.S. data covering the period 1960-2013 and data for nine Corn Belt states covering the period 1960-2004. Cost and cost share equations are specified and estimated, providing useful information on the speed and nature of technological change, with a special focus on GM technology. The results document the changing patterns of farm productivity under biotechnology. They find that biotechnology has contributed to speeding up productivity growth in the Corn Belt, but not at the U.S. level. The results also document the evolving biases in technological

11 Table 5 shows that, when negative, the cross-price elasticities are not statistically significant. Thus, our analysis does not find statistical evidence of complementary among inputs. 
change in agriculture, with a special focus on the demand for herbicides and insecticides. We find evidence that Bt technology has increased the bias in favor of fertilizer use. By reducing pest damages, this indicates that Bt technology makes it easier for the plant to benefit from fertilizer applications. We also find that HT technology has reduced the technical change bias in favor of herbicide use. Finally, we find evidence that farm demands for fertilizer, herbicide, and insecticide have become more inelastic, (i.e., less responsive to prices). Thus, although biotechnology has contributed to technological progress in agriculture, GM adoption has also been associated with a lower ability of farmers to adjust to changing market conditions.

Our results tend to support a growing literature regarding the impact of biotechnology in agriculture. For example, in the Corn Belt states, we find that the bias in technical change has changed from energy using before 1995 to energy saving after 1995. This result is consistent with HT technology being a complement to reduced tillage (Fernandez-Cornejo et al., 2012; Perry, Moschini, and Hennessy, 2016). We also document the heterogeneity in productivity both over time and across space. We find that, since 1995, agricultural productivity has increased faster in the Corn Belt than at the U.S. level, likely reflecting regional differences in biotechnology adoption. Finally, we documented evolving patterns of elasticities of farm input demands in the United States, with some trends toward more inelastic demands. Such trends raise several issues that appear to be policy relevant. The last few decades have seen a rise in concentration in farm input industries (Fuglie et al., 2012). Biotechnology firms have been vertically integrating into seed breeding and chemical production. In the presence of inelastic demand for inputs, increased concentration in farm input industries may contribute to the exercise of market power, leading to higher farm input prices. This change could have adverse effects on farm welfare and on the efficiency of agriculture. Exploring the economic and policy implications related to such issues appear to be good topics for future research.

\section{References}

Antle, J.M. “The Structure of U.S. Agricultural Technology, 1910-78." American Journal of Agricultural Economics 66,4(1984):414-21.

Ball, V.E., J.C. Bureau, R. Nehring, and A. Somwaru. "Agricultural Productivity Revisited.” American Journal of Agricultural Economics 79,4(1997):1045-63.

Ball, V.E., C. Hallahan, and R. Nehring. "Convergence of Productivity: An Analysis of the Catch-up Hypothesis within a Panel of States." American Journal of Agricultural Economics 86,5(2004):1315-21.

Barten, A.P. "Maximum Likelihood Estimation of a Complete System of Demand Equations." European Economic Review 1,1(1969):7-73.

Berndt, E.R., and D.O. Wood. "Technology, Prices and Derived Demand for Energy.” Review of Economics and Statistics 57,3(1975):259-68. 
Binswanger, H.P. "A Cost Function Approach to the Measurement of Factor Demand and Elasticities of Substitution." American Journal of Agricultural Economics 56,2(1974); 377-86.

Bustos, P., B. Caprettini, and J. Ponticelli. “Agricultural Productivity and Structural Transformation: Evidence from Brazil.” American Economic Review 106,6(2016):1320-65.

Carpenter, J. E.. "Peer-Reviewed Surveys Indicate Positive Impact of Commercialized GM Crops." Nature Biotechnology 28,4(2010):319-21.

Chambers, R. Applied Production Economics: A Dual Approach. Cambridge: Cambridge University Press, 1988.

Chavas, J.-P. “A Cost Approach to Economic Analysis under State-Contingent Production Uncertainty.” American Journal of Agricultural Economics 90,2(2008):435-46.

- "Structural Change in Agricultural Production: Economics, Technology and Policy." Handbook of Agricultural Economics 1A(2001):263-85.

Chavas, J.-P., G. Shi, and J. Lauer. "The Effects of GM Technology on Maize Yield.” Crop Science 54,4(2014):1331-35.

Diewert, W.E. "Fisher Ideal Output, Input, and Productivity Indexes Revisited.” Journal of Productivity Analysis 3,3(1992) 211-48.

Diewert, W.E., and T.J. Wales. "Flexible Functional Forms and Global Curvature Conditions." Econometrica 55,1(1987):43-68.

Fernandez-Cornejo, J., C. Hallahan, R. Nehring, S. Wechster, and A. Grube. "Conservation Tillage, Herbicide Use and Genetically Engineered Crops in the United States: The Case of Soybeans." AgBioForum 15,3(2012):231-41.

Fernandez-Cornejo, J., and S. Jans. "Quality-Adjusted Price and Quantity Indices for Pesticides.” American Journal of Agricultural Economics 77,3(1995):645-59.

Fernandez-Cornejo, J., S.J. Wechsler, M. Livingston, and L. Mitchell. Genetically Engineered Crops in the United States. Washington, DC: U.S. Department of Agriculture, Economic Research Service, Economic Research Report No. 162, 2014.

Fuglie, K., P. Heisey, J. King, and D. Schimmelpfennig. "Rising Concentration in Agricultural Input Industries Influences New Farm Technologies.” Amber Waves 10(December 2012):1-6.

Gardner, J.G., R.F. Nehring, and C.H. Nelson. "Genetically Modified Crops and Household Labor Savings in US Crop Production.” AgBioForum 12,3-4(2009):303-12.

Klümper, W., and M. Qaim. “A Meta-Analysis of the Impacts of Genetically Modified Crops.” PLOS ONE 9,11(2014):e111629.

LaFrance, J.T., and R.D. Pope. "Duality Theory for Variable Costs in Joint Production." American Journal of Agricultural Economics 92,3(2010):755-62.

Lopez, R.E. "Analysis of a Small Open Economy: The Case of Energy Prices in Canada." American Journal of Agricultural Economics 64,3(1982):510-19.

Lusk, J.L., J.B. Tack, and N.P. Hendricks. "Heterogeneous Yield Impacts from Adoption of Genetically Engineered Corn and the Importance of Controlling for Weather." National Bureau of Economic Research (NBER) Working Paper No. 23519, Cambridge, MA: NBER, 2017.

Perry, E.D., F. Ciliberto, D.A. Hennessy, and G. Moschini. "Genetically Engineered Crops and Pesticide Use in U.S. Maize and Soybeans.” Science Advances 2,8(2016):e1600850.

Perry, E.D., G. Moschini, and D.A. Hennessy. "Testing for Complementarity: Glyphosate Tolerant Soybeans and Conservation Tillage." American Journal of Agricultural Economics 98,3(2016):765-84. 
Pope, R.D., and J.-P. Chavas. "Cost Functions under Production Uncertainty." American Journal of Agricultural Economics 76,2(1994):196-204.

Ray, S.C. “A Translog Cost Function Analysis of U.S. Agriculture, 1939-77.” American Journal of Agricultural Economics 64,3(1982):490-98.

Tack, J., R. Pope, J. LaFrance, and R. Cavazos. “Modeling an Aggregate Agricultural Panel with Application to U.S. Farm Input Demands.” European Review of Agricultural Economics 42,3(2015):371-96.

U.S. Department of Agriculture, Economic Research Service. "Data Products: Adoption of Genetically Engineered Crops in the U.S.” 2017a. Internet site: https://www.ers.usda. gov/data-products/adoption-of-genetically-engineered-crops-in-the-us.aspx (Accessed March 18, 2018).

U.S. Department of Agriculture, Economic Research Service. "Data Products: Agricultural Productivity in the U.S.” 2017b. Internet site: https:/www.ers.usda.gov/data-products/ agricultural-productivity-in-the-us.aspx (Accessed March 18, 2018).

Wang, S.L., P. Heisey, D. Schimmelpfennig, and E. Ball. Agricultural Productivity Growth in the United States: Measurement, Trends and Drivers. Washington, DC: U.S. Department of Agriculture, Economic Research Service, Economic Research Report No. 189, 2015.

Xu, Z., D.A. Hennessy, K. Sardana, and G. Moschini. "The Realized Yield Effect of Genetically Engineered Crops: U.S. Maize and Soybean.” Crop Science 53,3(2013):735-45. 